\title{
Depoimento de um imigrante japonês sobre seus primeiros anos de experiência escolar no Brasil
}

\section{Report of a Japanese immigrant about his first years \\ of school experience in Brazil}

\author{
Elissa HANAYAMA
}

\section{RESUMO}

Este depoimento refere-se aos primeiros anos de estudos $\left(1^{\mathrm{a}}\right.$ a $4^{\mathrm{a}}$ série do Ensino Fundamental I), de uma criança japonesa que teve que deixar o seu país de origem aos sete anos, tendo que se adaptar a uma cultura e educação totalmente diferente.

Palavras-chave: Educação, Japão, Hiraganá, Sensei, Alambari/ Brasil, imigrante.

\begin{abstract}
This report is about the first years' studies of a Japanese child $\left(1^{\text {a }}\right.$ until $4^{\text {a }}$ grade - Elementary School), who left his country and had to adapt himself to a culture and education totally different.

Index terms: Education, Japan, Hiragana, teacher, Alambari/ Brazil, immigrant.
\end{abstract}




\section{Introdução:}

Depoimento dado pelo meu pai, Kunio Hanayama, no dia 03 de abril de 2007, em São Paulo, sobre a transição educacional em sua vida

Este depoimento foi colhido por mim, Elissa Hanayama, estudante de Pedagogia do $7^{\circ}$ semestre da Universidade de São Paulo, e filha mais nova de Kunio Hanayama, um imigrante japonês no Brasil. Foi realizado sob a orientação da Dra. Nilce da Silva, professora da disciplina Fundamentos/ Metodologia do Ensino de Jovens e Adultos da Faculdade de Educação da Universidade de São Paulo.

Este retrato se refere ao período pós Segunda Guerra Mundial, momento em que, 1948, Yukishige Tamura é eleito vereador em São Paulo, tornando-se, assim, o primeiro nikkey - descendente de japonês nascido no exterior- a ocupar um cargo eletivo em uma capital. Já em clima de paz, é restabelecido, em 1949, o comércio entre Brasil e Japão por meio de um acordo bilateral. Um ano depois, o Governo Federal do Brasil anuncia a liberação dos bens confiscados aos imigrantes dos países do Eixo, e, em 1951, aprova projeto para introdução no País de cinco mil famílias imigrantes. Encorajadas, as empresas japonesas começa a planejar investimentos no Brasil. As primeiras delas chegam em 1953. Com os novos investimentos feitos pelas empresas japonesas no Brasil, muitas famílias imigraram para este país. E, neste contexto, após um ano de estudo ${ }^{1}$ em sua terra, Kunio deixou o Japão aos sete anos, em 1955.

Depois de viajar por dois meses em um navio, o pequeno aportou com seus pais e irmãos em Santos, seguindo para a cidade de Alambari, onde retornou aos seus estudos.

\footnotetext{
${ }^{1}$ Veja as fotos n. 1 e 2 no final deste trabalho.
} 
Minha primeira escola no Brasil foi em Alambari, na cidade de Itapetininga, em 1955. A sala era mista, de $1^{\circ}$ ao $4^{\circ}$ ano, acho... Ou era só $1^{a}$ e $2^{a}$ série?

A maior diferença que eu senti foi com relação à língua, e à qualidade também. No Japão, a escola era de concreto armado e alvenaria, era a escola modelo de Sabae. Lá se ensinava hiraganá, que era assim: A, I, $U, E, O ; K A, K I, K U, K E, K O ; N A, N I, N U, N E . N O ; S A, S H I, S U, S E, S O .$. Até 56 vogais.

Lá se ensinava também ler as horas, era bem divertido. Nas férias, a professora pedia pra fazer um diário, contando de tudo o que fazíamos. $O$ caderno era um quadradinho branco, se escrevia na vertical, da direita pra esquerda, de cima para baixo. Depois de escrever o texto tínhamos que desenhar também e se fôssemos passear no mato, era pra trazer uma cigarra. Não me lembro de outros alunos, mas minha tarefa foi trazer uma cigarra, viva, em uma caixinha. Daí colocava o nome do inseto, a espécie, as características dela, tudo em um papelzinho na caixinha que prendi com um alfinete.

Todos os dias os alunos ficavam enfileirados e o sensei- mestre, em japonês- ficava lá na frente ensinando como se escovava os dentes. Ele escovava junto com a gente, dizia: 1, 2, 3...

Todo ano tinha o ensoku que era uma caminhada com piquenique. Pegávamos o bondinho da cidade com o professor, ele sozinho levava a gente, era pertinho. E tinha também o undokai, que é gincana. Essa era uma atividade que fazia parte do curso letivo.

O entrevistado se mostrou bastante empolgado ao contar as lembranças da escola do Japão. Apesar de breve, este seu relato lhe foi muito agradável.

Já ao falar sobre a escola que encontrou no Brasil, a empolgação diminuiu. 
Já no Brasil, era bem diferente, não tinha excursão, por exemplo. No primeiro ano em Alambari, a escola era muito precária! A professora, às vezes, vinha; às vezes, não vinha; faltava mais do que vinha. Ela vinha na jardineira, que é aquele caminhão que trazia frutas de Itapetininga, eram 18 quilômetros de viagem, vinha dar aula pra gente.

O material da escola era caderno brochura, de caligrafia, em que eu copiava várias vezes a mesma letra e o livro "Caminho Suave”- a cartilhaque agente usava até a $4^{a}$ série. Pra entrar na sala de aula a gente cantava o Hino Nacional. Mas a escola era muito precária mesmo, não se oferecia material, não tinha nada de livro de leitura. O que eu lia era fora da escola e aquilo que eu ganhava. Eu me lembro que eu lia muito o "Jeca Tatu”, um reclame que vinha num livrinho pequeno que entregavam na escola, do Biotônico Fontoura ${ }^{2}$. Aparecia o Jeca, lá, descalço. Daí entrava o bichinho no pé e ele ficava mal, com amarelão, barrigudo... Daí era só tomar o Biotônico Fontoura e virava empresário, fazendeiro... Até os porcos usavam sapatinho, sabe? Eu lia também “O Diário de Dona Benta”... Não, era “Geografia de Dona Benta”, um livro bem grosso.

Eu não sabia falar nada (em português) quando cheguei em Alambari! Eu me lembro das primeiras músicas que ouvi aqui no Brasil, tocavam à noite, naqueles auto- falantes da praça, era assim: “Oi tava na peneira, oi tava namorando, oi tava na, na, na, na...”, tinha também: “Ôôô baiano da Serra Grande...”, esta música foi o primeiro nissei que cantou. Ah! Tinha aquela que era assim: “O rio vermelhoooo, oh, oh!”, assim, meio country, americano, na vitrola de agulha e manivela. (Risos)

Me lembro de outro livro, que eu gostei muito, chama-se “20.000 Milhas do Fundo do Mar”, de Júlio Verne, em 1958, 59. Era sobre um submarino. Bem legal!

\footnotetext{
${ }^{2}$ Fortificante muito usado para ser ministrado às crianças.
} 
Na escola, quando a professora entrava, todo mundo tinha que levantar, $e$ só se sentar depois que ela se sentava. No começo, quando não entendia nada, todo mundo sentava, e eu ficava lá em pé, eram meus colegas que me avisavam pra sentar.

De manhã tinha aula de japonês, na casa de um dos colonos, era com um amigo. Iam umas 10 ou 12 crianças, o nome do sensei era Ota, era o Ota sensei, como o chamávamos. Todo mundo morava em torno de 10, 12 quilômetros, e ia todo mundo lá, estudar, porque se achava importante manter o idioma da pátria. Ele veio do Japão e se voluntariou para alfabetizar aqui no Brasil, ele já era bem velhinho, e veio trazer a cultura pra gente. Fiquei com ele os dois anos em que fiquei em Alambari. Somente à tarde que eu ia pra escola, aprender português, na escola municipal.

Em matemática, tínhamos que decorar a tabuada, $2 \times 1=2,2 \times 3=6$, $3 \times 3=9 . .$. Eu tinha matemática, português... De manhã a gente aprendia a cantar o Hino Japonês, fazia leitura, escrever hiraganá e katakaná conjunto de sons do japonês. O ensino de matemática, na conta de dividir é diferente da do Brasil, era uma conta mais fácil, rápida e prática de fazer, com o sinal de divisão ao contrário do que a gente aprende aqui. A chave, sabe, era ao contrário.

Acho que, se eu tivesse concluído os estudos no Japão, a qualidade teria sido bem melhor. Aqui no Brasil, além de eu ter passado pela dificuldade da mudança de língua e cultura, a educação era ruim, até mesmo porque eu tive uma professora muito ausente no início de meus estudos. Mas não reclamo não! Estudei até o final, tive que fazer cursinho. Conheci gente bacana pelo caminho e consegui fazer a universidade. Das dificuldades que tive e como eu as solucionei, eu não teria aprendido em nenhuma escola, aprendi apenas mudando de país. Minha conclusão é de que valeu muito à pena. 
Fotos n. 1 e 2

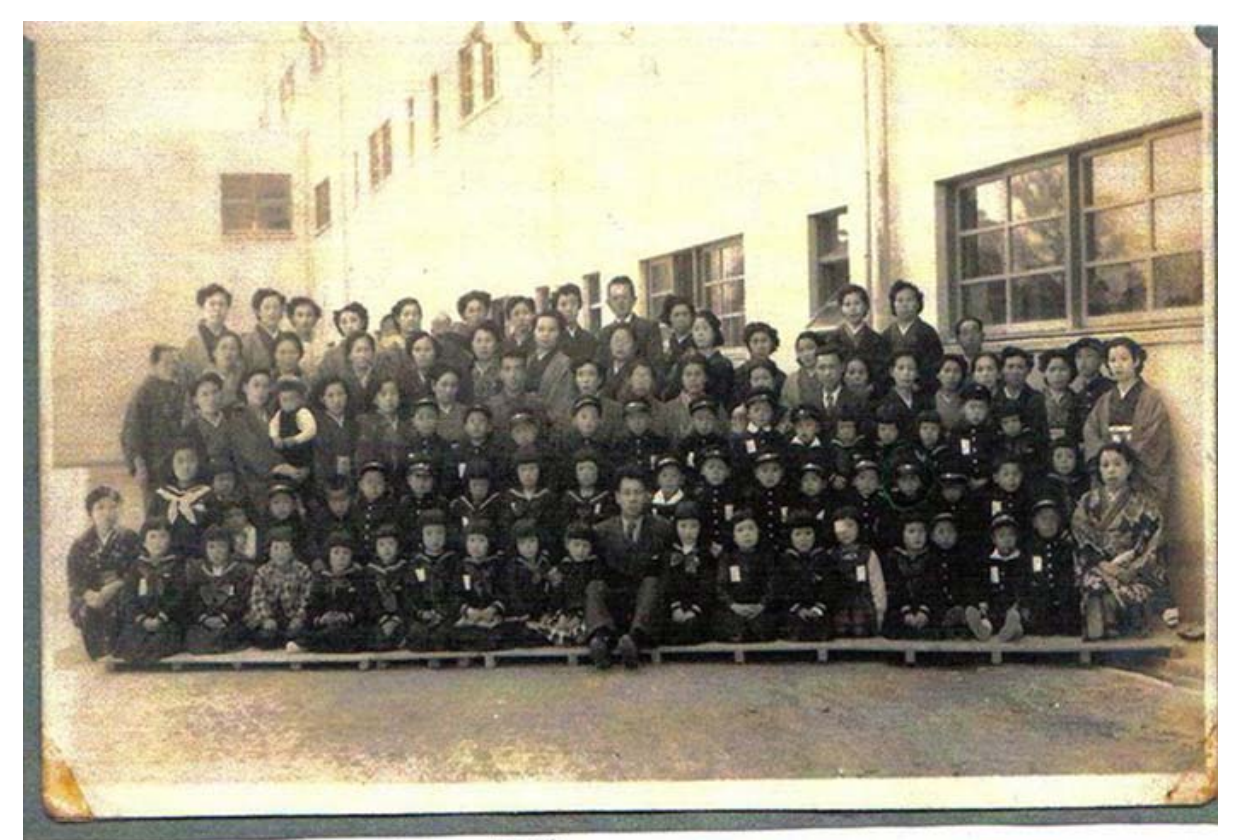

escola modelo SEKINKo, 1954

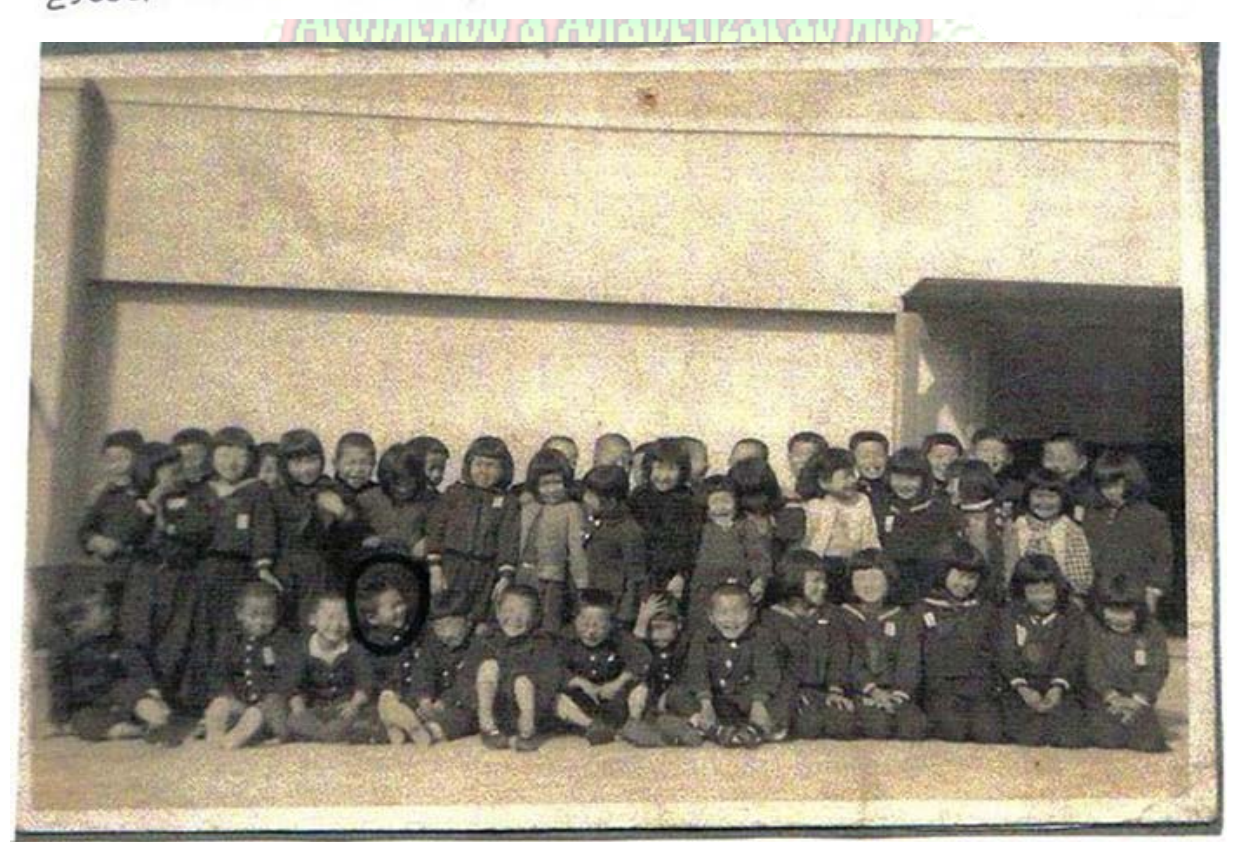

1954 


\section{Autora:}

\section{Elissa Hanayama}

Graduanda em Pedagogia na Faculdade de Educação da Universidade de São

elissaya@gmail.com

\section{Como citar este depoimento:}

HANAYAMA, Elissa. Depoimento de um imigrante japonês sobre seus primeiros anos de experiência escolar no Brasil . Revista ACOALFAplp: Acolhendo a Alfabetização nos Países de Língua portuguesa, São Paulo, ano 2, n. 4, 2008. Disponível em: <http://www.mocambras.org> e ou <http://www.acoalfaplp.org>. Publicado em: março 2008.

Recebido em junho/ 2007 - Aprovado em agosto/ 2007 